\title{
Endovascular Approach to Acute Superior Mesenteric Artery Thrombosis Associated with Progesterone Use
}

\author{
Pratik Shah $^{1}$ Krishna Mundada ${ }^{2}$ Vimal Someshwar $^{1}$
}

${ }^{1}$ Department of Radiology, Kokilaben Dhirubhai Ambani Hospital and Medical Research Institute, Mumbai, Maharashtra, India

2 Dr. R. N. Cooper Hospital, Mumbai, Maharashtra, India

J Clin Interv Radiol ISVIR 2022;6:229-230.

We would like to report the case of superior mesenteric arterial thrombosis in a woman with a history of progesterone intake. A 51-year-old woman with a history of progesterone consumption for delayed menstrual cycles and menorrhagia, presented with severe abdominal pain, nausea, and a 1-day history of constipation. A contrast-enhanced computed tomography (CT) scan revealed near-total occlusion of $4.4 \mathrm{~cm}$ of the superior mesenteric artery from its origin (-Fig. 1).

Subsequently, Digital Subtraction Angiography (DSA) confirmed the thrombosis of the superior mesenteric artery ( - Fig. 2A) and at the same setting, thromboaspiration was performed ( - Fig. 2B). Residual-narrowing was noted in the post aspiration angiogram (-Fig. 2C). After 2 days of inten-

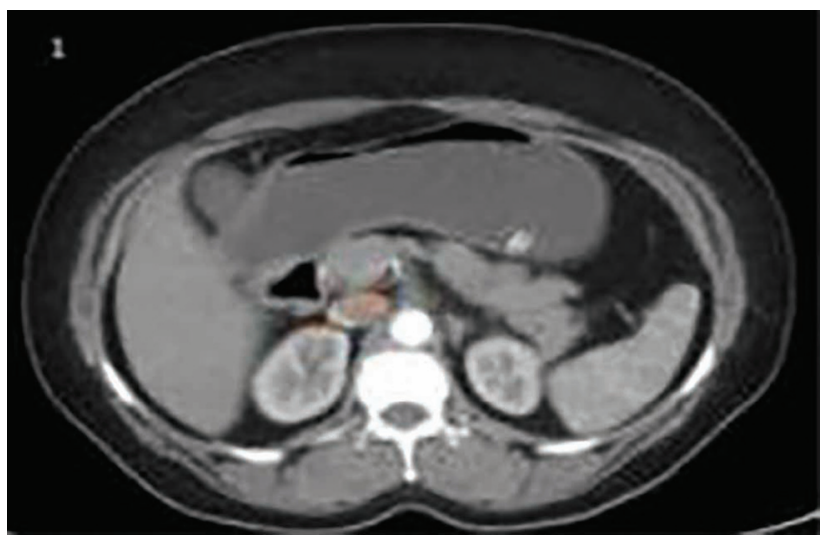

Fig. 1 CT scan axial arterial phase showing superior mesenteric artery thrombosis. Note the unenhanced lumen of the artery from its origin.
Address for correspondence Krishna Mundada, H. B. T. Medical College and Dr. R. N. Cooper Hospital, JVPD Scheme, Juhu, Mumbai, Maharashtra, 400056, India

(e-mail: mundadakrishnavinod29@gmail.com).

sive care unit (ICU) care, a repeat CT angiography showed recanalization of the superior mesenteric artery for a short segment with severe luminal narrowing by eccentric plaque, and non-enhancing bowel thinning was observed in the jejunum indicating ischemia, minimal ascites, and a bulky uterus ( - Fig. 3A). The patient was put on antiplatelet drugs


Fig. 2 (A-C) DSA scans during and after interventional procedures in the patient. SMA thrombosis in a lateral view, scan before thromboaspiration (A). Post aspiration DSA scan showing partially restored blood flow (B). Residual stenosis is still noted post aspiration (C).
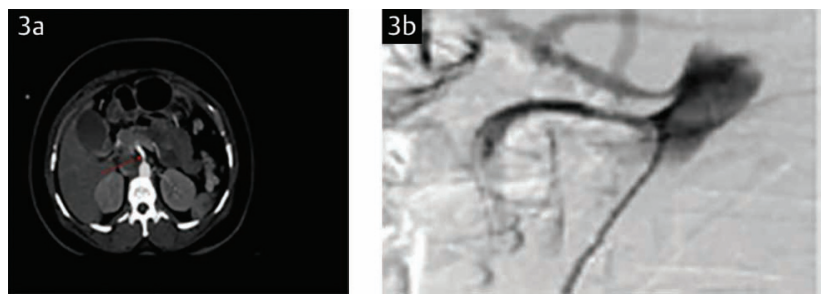

Fig. 3 (A) CT axial and lateral views of abdominal angiogram showing improved flow through the superior mesenteric artery after thromboaspiration. However, residual narrowing is still noted at the SMA osteum (arrow) (A). DSA scan showing the arterial blood supply completely restored after successful stent placement (B). article published online March 11, 2021
DOI https://doi.org/

10.1055/s-0041-1737025. ISSN 2457-0214. (c) 2021. Indian Society of Vascular and Interventional Radiology. All rights reserved.

This is an open access article published by Thieme under the terms of the Creative Commons Attribution-NonDerivative-NonCommercial-License, permitting copying and reproduction so long as the original work is given appropriate credit. Contents may not be used for commercial purposes, or adapted, remixed, transformed or built upon. (https://creativecommons.org/ licenses/by-nc-nd/4.0/)

Thieme Medical and Scientific Publishers Pvt. Ltd., A-12, 2nd Floor, Sector 2, Noida-201301 UP, India 
and a balloon expanding stent placement was performed without any complication (-Fig. 3B).

However, postprandial abdominal pain continued, this led to the termination of clopidogrel and scheduling of explorative laparotomy. A $10-\mathrm{cm}$ distal ileal loop and $20-\mathrm{cm}$ jejunal loop were found ischemic that were resected, and an end-toend anastomosis was performed.

Several cases of mesenteric venous thrombosis occurring in patients using progesterone pills have been reported. ${ }^{1,2}$ However, arterial thrombosis in patients using progesterone is uncommon. In our case, the woman was consuming progesterone and was scheduled for dilation and curettage when she developed SMA thrombosis.

Diagnosis of SMA thrombosis is difficult due to nonspecific and vague symptoms. ${ }^{3}$ Thrombotic occlusion of the artery is known to have an overall mortality rate of $77.4 \%$ compared with embolic occlusion that has a mortality rate of $54.1 \%{ }^{4}$ Laparotomy may be done to have a second look at the condition of the intestine, identify viable loops, and resect the infarcted bowel. Arterial thrombosis in patients on progesterone pills is rare, it is important to consider this in patients presenting with acute bowel ischemia.

\section{Conflict of Interest}

None declared.

\section{References}

1 Stewart H, Flannery MT, Humphrey DA. Superior mesenteric vein thrombosis secondary to oral contraceptive use. Case Rep Vasc Med 2012;2012:969130

2 Rawla P, Pradeep Raj J, Thandra KC, Bandaru SS. Superior mesenteric vein thrombosis in a patient on oral contraceptive pills. Gastroenterol Res 2017;10(06):380-382

3 Kozuch PL, Brandt LJ. Review article: diagnosis and management of mesenteric ischaemia with an emphasis on pharmacotherapy. Aliment Pharmacol Ther 2005;21(03):201-215

4 Schoots IG, Koffeman GI, Legemate DA, Levi M, van Gulik TM. Systematic review of survival after acute mesenteric ischaemia according to disease aetiology. Br J Surg 2004;91 (01):17-27 